\title{
Mechanical and vibration testing of carbon fiber composite material with embedded piezoelectric sensors
}

\author{
Kirsten P. Duffy*a, Bradley A. Lerch ${ }^{\mathrm{b}}$, Nathan G. Wilmoth ${ }^{\mathrm{c}}$, \\ Nicholas Kray ${ }^{\mathrm{d}}$, and Gregory Gemeinhardt ${ }^{\mathrm{d}}$ \\ ${ }^{a}$ Univ. of Toledo/NASA Glenn Research Center, 21000 Brookpark Rd., Cleveland, OH, USA 44135 \\ ${ }^{\mathrm{b}}$ NASA Glenn Research Center, 21000 Brookpark Rd., Cleveland, OH, USA 44135 \\ ${ }^{\mathrm{c}}$ ASRC/NASA Glenn Research Center, 21000 Brookpark Rd., Cleveland, OH, USA 44135 \\ ${ }^{\mathrm{d}}$ GE Aviation, 1 Neumann Way, Evendale, OH 45215
}

\begin{abstract}
Piezoelectric materials have been proposed as a means of decreasing turbomachinery blade vibration either through a passive damping scheme, or as part of an active vibration control system. For polymer matrix fiber composite (PMFC) blades, the piezoelectric elements could be embedded within the blade material, protecting the brittle piezoceramic material from the airflow and from debris. Before implementation of a piezoelectric element within a PMFC blade, the effect on PMFC mechanical properties needs to be understood. This study attempts to determine how the inclusion of a packaged piezoelectric patch affects the material properties of the PMFC. Composite specimens with embedded piezoelectric patches were tested in four-point bending, short beam shear, and flatwise tension configurations. Results show that the embedded piezoelectric material does decrease the strength of the composite material, especially in flatwise tension, attributable to failure at the interface or within the piezoelectric element itself. In addition, the sensing properties of the post-cured embedded piezoelectric materials were tested, and performed as expected. The piezoelectric materials include a non-flexible patch incorporating solid piezoceramic material, and two flexible patch types incorporating piezoelectric fibers. The piezoceramic material used in these patches was Navy Type-II PZT.
\end{abstract}

Keywords: Piezoelectricity, polymer matrix fiber composite, damping, aircraft engine blades, PZT-5A, Type-II PZT

\section{INTRODUCTION}

\subsection{Turbomachinery blade damping}

As part of the Fundamental Aeronautics program, researchers at NASA Glenn Research Center (GRC) are investigating new technologies supporting the development of lighter, quieter, and more efficient fans for turbomachinery applications. One such application is commercial fixed wing, powered flight. High performance fan blades designed to achieve such goals will be subjected to higher levels of aerodynamic excitations which could lead to more serious and complex vibration problems ${ }^{1}$. One design approach is to manufacture these fan blades from polymer matrix fiber composite (PMFC). This material system is advantageous in that fibrous material orientations can be optimized to provide the desired strength in a low weight system. As this fan blade material system is optimized, the resulting blade becomes thinner, leading to potential frequency excitation from sources such as inlet distortion and adjacent hardware. Adding damping treatments to blades can alleviate these vibrations; however, designing damping treatments for rotating blades in an engine environment is difficult because of extreme temperatures and centrifugal accelerations. Since a damping treatment must not affect the aerodynamics of the blade, it must be internal to the blade, out of the air stream, or applied to the blade surface in a thin layer. In addition to that, it is extremely challenging to design damping systems that can withstand the harsh engine environment and still remain both cost-effective and easy to produce.

*Kirsten.P.Duffy@ nasa.gov; phone 1216 433-3880 
Several damping methods have been investigated at NASA GRC for use in aircraft engines, including viscoelastic damping, impact damping, plasma sprayed damping coatings, and high-damping, high-temperature shape memory alloys. The current effort seeks to investigate piezoelectric materials as part of an active control system to see if this technology is a viable alternative. Since the piezoelectric materials will likely need to be integrated with the blade structure, the effect of embedding on the composite mechanical properties must be understood.

\subsection{Piezoelectric damping}

Piezoelectric materials have been proposed as a means of decreasing engine blade vibration either through a passive damping scheme, or as part of an active vibration control system. For polymer matrix fiber composite (PMFC) blades, the piezoelectric elements could be embedded within the blade material, protecting the brittle piezoceramic material from the airflow and from debris.

The piezoelectric damping idea has been investigated by many researchers over the years, with tests and analysis showing significant mechanical vibration reduction. The idea is to place packaged transducers incorporating piezoceramic material within the blade in areas of high modal stress. When a load is placed on the piezoelectric element, a voltage is induced, allowing it to function as a sensor. Conversely, when a voltage is placed on a piezoelectric element, strain is induced, allowing it to function as an actuator. For passive damping, an electrical shunt circuit is placed across the terminals of the piezoelectric patch, which then dissipates the electrical energy induced in the circuit by the blade motion. For active control, the piezoelectric sensor signal goes to a control system, which then sends an amplified signal to the piezoelectric actuator, counteracting the motion of the blade. More on piezoelectric damping can be found in a survey of state-of-the art smart structures in Chopra ${ }^{2}$. An analytical method to determine the effective damping of a shunted piezoelectric material can be found in Hagood and von Flotow ${ }^{3}$. Lesieutre ${ }^{4}$ described the different types of shunt circuits and how they affect vibration behavior.

\subsection{Mechanical properties of piezoelectric-embedded polymer matrix fiber composites}

Before implementation of a piezoceramic within a PMFC blade, the effect on composite mechanical properties needs to be understood. Researchers have investigated the effect of sensor embedding on composite strength, mostly on sensors that were fully embedded within the composite material. Tensile and fatigue tests were performed by Warkentin and Crawley ${ }^{5}$ on silicon chips embedded in thin graphite/epoxy test specimens. They focused on techniques for proper embedding, and looked at the functionality of the chips within the specimen under loading. They found that the failure mode was typically at the electrical connection to the chip. They also measured some reduction in strength in the test articles with the embedded chips, regardless of chip functionality. Bronowicki et al. ${ }^{6}$ tested monolithic Navy type I and II lead zirconate titanate (PZT) elements embedded in composite specimens, looking at tension, compression, temperature, and fatigue effects. They measured the piezoelectric properties throughout testing, showing the degradation with tensile strain up to $4000 \times 10^{-6} \mathrm{~m} / \mathrm{m}$, and with temperature cycling of -100 to $+100^{\circ} \mathrm{C}$. Mall et al. ${ }^{7,8}$ tested monolithic piezoelectric elements embedded in composite specimens, looking at sensor voltage output under tensile and fatigue tests, and fatigue testing of the piezoelectric element when used as an actuator. They found that the tensile strength and Young's modulus with and without PZT were within 4\% of each other. They tested PZT-embedded graphite/epoxy specimens for fatigue, in combined electrical and mechanical loading. Paget and Levin ${ }^{9}$ performed tensile and compressive testing on composite specimens with embedded monolithic PZT elements. Tensile tests showed only a $4.5 \%$ reduction in strength, while compressive tests had no reduction in strength. Here the PZT element was placed in the midplane, and buckling was suppressed. Lin and Chang ${ }^{10}$ developed a method of manufacturing piezoceramic networks onto a thin flexible layer (SMART Layer), and performed mechanical testing of four different graphite/epoxy composites with either the SMART Layer substrate material alone (without circuits or piezoelectric elements) or the full SMART Layer with piezoelectric elements. The specimens with the SMART layer substrate material alone were tested in flatwise tension, double-lap shear, short beam shear, and quasi-static impact, with little difference between the baseline and substrate-layer-embedded specimens. The SMART Layer used in the compression test included a series of $6.35 \mathrm{~mm}$ diameter PZT discs placed $10.2 \mathrm{~cm}$ apart, along with circuit wires. Compression test results again indicate little difference between the baseline and embedded panels, with failure occurring because of laminate compression failure and not at the SMART Layer. Konka et al. ${ }^{11}$ ran mechanical tests of foam sandwich structures with flexible piezoelectric fiber composite sensors embedded within the glass-fiber/epoxy face skins. Tensile tests showed a 7\% reduction in strength due to the sensors, while there was a $5.4 \%$ reduction in short beam shear and $3.6 \%$ reduction in flexural strength. The fatigue lives were very similar between baseline and piezoelectric-embedded specimens. 
This study looks at how the inclusion of a packaged piezoelectric element affects the material properties of solid PMFC specimens. Panels are made with and without commercially available piezoelectric patches embedded into PMFC material. Test articles are then cut from the panels so that the piezoelectric material forms a full layer within the composite in the direction or plane transverse to the induced stress (not fully surrounded by composite). These articles are then tested in four-point bending, short beam shear, and flatwise tension configurations. The transducers include a non-flexible patch incorporating a solid piece of piezoelectric material (monolithic), and two flexible piezoelectric patches with machined and extruded piezoelectric fibers.

A second goal of this research is to assess the effect of the embedding process on the functionality of the piezoelectric patch, after experiencing a composite curing temperature of $175^{\circ} \mathrm{C}\left(350^{\circ} \mathrm{F}\right)$ and a pressure of $690 \mathrm{kPa}(100 \mathrm{psi})$. This was done by testing the sensing ability of embedded sensors within vibrating composite beams. Damping and vibration control test results will be reported in a future paper.

\section{MECHANICAL TESTING}

In mechanical testing, the strength of the composite material with an embedded piezoelectric sensor was evaluated using three different tests - four-point bending, short-beam shear, and flatwise tension.

\subsection{Mechanical testing setup}

All testing was performed on PMFC with and without embedded packaged piezoelectric elements. Table 1 describes the three different piezoelectric patch types that were used, as well as information on the PMFC. The patches all incorporate Navy Type-II PZT (PZT-5A) material. Each piezoelectric patch consists of the PZT material in the midplane of the patch, with electrodes on either side of the piezoelectric material, and a polymer film protective covering, all held together with adhesive. A description of the fabrication method for one of the piezoelectric patch types is given by Bryant. $^{12}$ The non-flexible monolithic patch includes a sheet of solid piezoelectric material. One of the flexible patches includes piezoelectric fibers with a rectangular cross-section which are made by machining a monolithic piece of PZT. The second flexible patch includes extruded PZT fibers with a circular cross section.

Table 1. Composite material and piezoelectric element descriptions

\begin{tabular}{|c|c|c|}
\hline Composite Material & Type & Description \\
\hline $\begin{array}{c}\text { Polymer matrix fiber } \\
\text { composite (PMFC) }\end{array}$ & $\begin{array}{c}\text { HexPly 8551-7 } \\
\text { with IM 7 carbon fibers }\end{array}$ & $\begin{array}{c}\text { Epoxy resin with unidirectional carbon } \\
\text { fibers, ply stack-up }\end{array}$ \\
\hline Piezoelectric Elements & Type & Description \\
\hline Monolithic & Non-flexible, PZT-5A, solid material & $250 \mu \mathrm{m}(0.010$ ”) thick PZT \\
\hline Flexible-1 & Flexible, PZT-5A, rectangular fibers & $175 \mu \mathrm{m}(0.007$ ”) thick PZT fibers \\
\hline Flexible-2 & Flexible, PZT-5A, circular fibers & $250 \mu \mathrm{m}(0.010$ ”) thick PZT fibers \\
\hline
\end{tabular}

Embedding was done by substituting the piezoelectric patch for layers of composite ply within each test article. An area was cut out from two plies with dimensions equal to the piezoelectric patch dimensions, and panels assembled as shown in Figure 1. Test articles were then cut directly from these panels for mechanical testing. The vibration test beams, however, were used as laid-up. The composite was cured at $175^{\circ} \mathrm{C}\left(350^{\circ} \mathrm{F}\right)$ and held under a pressure of $690 \mathrm{kPa}(100$ psi) for two hours.

Three kinds of tests were performed on the test specimens as described in Table 2 - four-point bending, short beam shear, and flatwise tensile testing. Since standard in-plane tensile test results had already been published in the literature ${ }^{6-9}$, they were not performed as part of this work. Prior to testing, all the samples were dried at $240^{\circ} \mathrm{F}$ for six hours, and placed in a desiccation chamber immediately after being baked. A speckle pattern was painted onto one edge 
of each specimen, and displacement was measured during each test using photogrammetry. This method allows observation of localized high-strain areas within the test specimen.

Figures 2 and 3 show the specimen fabrication and testing configurations. In each specimen, the PZT element comprised a full layer in the direction or plane transverse to the induced stress. In the 4-point bending test, the sample is inserted into the machine and held at approximately $10 \mathrm{lbf}$. Then a ramp wave is run at 0.05 inches per minute, and the peak load is recorded. For the short beam shear test, the sample is inserted into the machine and held at about $2 \mathrm{lbf}$. Again, a ramp wave of 0.05 inches per minute is run, and the peak force is recorded. For the flatwise tension test, two bolts are glued to the composite material with epoxy. The sample is held at about $10 \mathrm{lbf}$ in the machine. The bolts are then pulled apart at a rate of 0.005 inches per minute, and the peak force is recorded. Each test was performed on baseline composite-only samples and on samples with embedded piezoelectric elements.

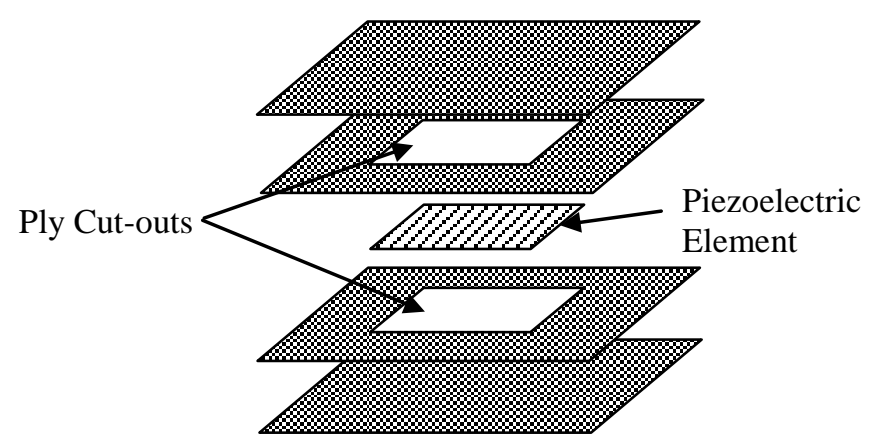

Figure 1. Assembly of piezoelectric element in composite.

Table 2. Mechanical test configurations.

\begin{tabular}{|c|c|c|c|}
\hline Test Type & Standard & Specimen Dimensions & Piezoelectric Location \\
\hline 4-Point Bending & ASTM D7264 ${ }^{13}$ & $\begin{array}{l}165 \mathrm{~mm} \times 12.7 \mathrm{~mm} \times 4.72 \mathrm{~mm} \\
(6.5 " \mathrm{x} 0.5 ” \times 0.186 ")\end{array}$ & $\begin{array}{l}\text { Two patches, piezo surface } 0.3 \mathrm{~mm} \\
(0.012 ") \text { below PMFC surface }\end{array}$ \\
\hline Short Beam Shear & ASTM D $2344^{14}$ & $\begin{array}{l}76 \mathrm{~mm} \times 25 \mathrm{~mm} \times 12.7 \mathrm{~mm} \\
(3.0 " \times 1.0 " \times 0.5 ")\end{array}$ & One patch located at midplane \\
\hline Flatwise Tension & ASTM D $729^{15} 1$ & $\begin{array}{l}22 \mathrm{~mm} \text { diameter } \times 20 \mathrm{~mm} \text { thick } \\
(0.88 \text { " dia. } \mathrm{x} 0.78 \text { " thick })\end{array}$ & One patch located at midplane \\
\hline
\end{tabular}



(a) Four-point bending and short beam shear

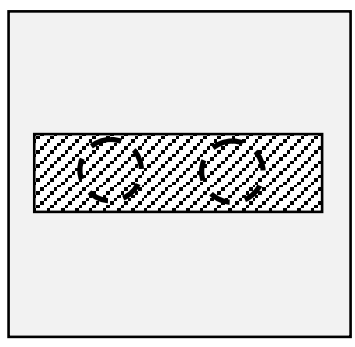

(b) Flatwise tension

Figure 2. Specimen fabrication. 


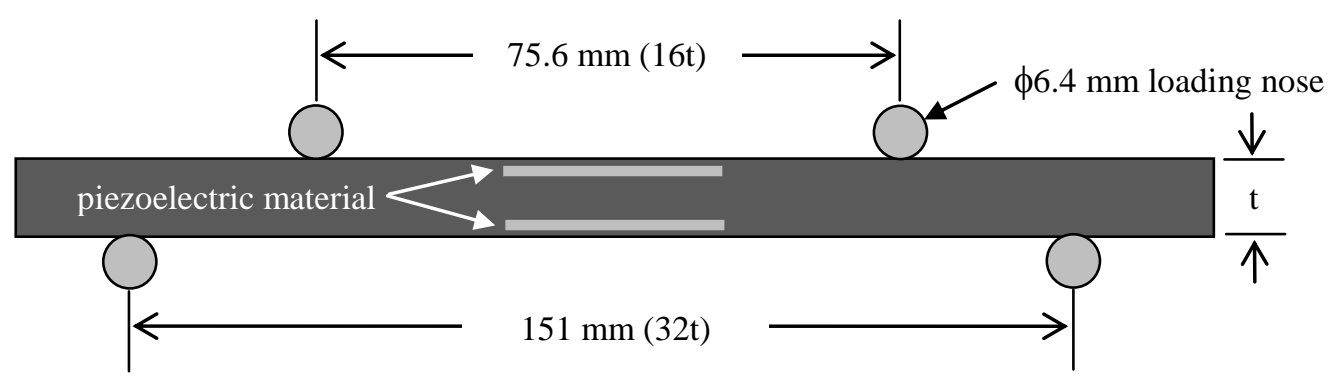

(a) 4-Point Bending Configuration

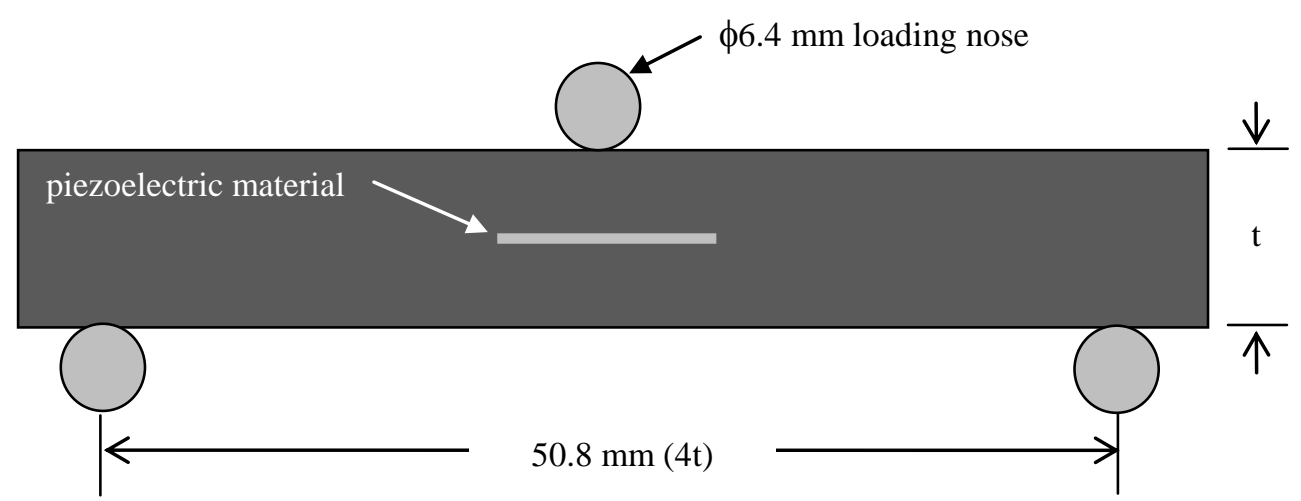

(b) Short Beam Shear Configuration

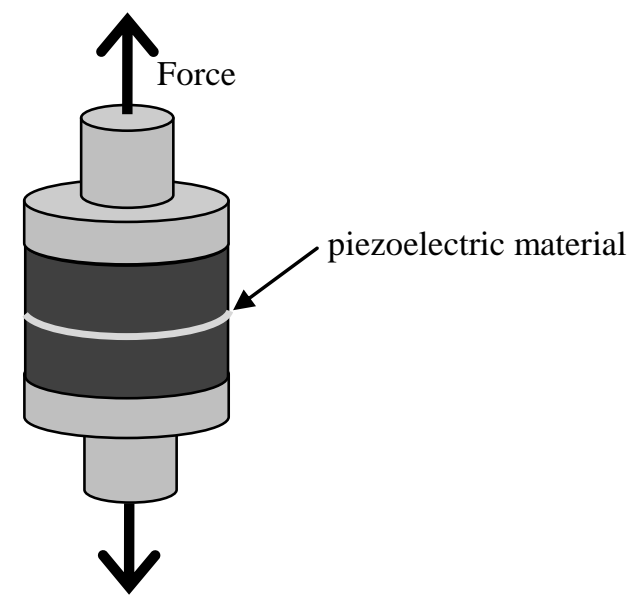

(c ) Flatwise Tension Configuration

Figure 3. Mechanical testing configurations.

\subsection{Four-point bending test results}

Figure 4 shows a baseline test sample in the four-point bending fixture. Two rollers applied a load to the top of the test specimen. There were three baseline samples. When the first sample was tested, failure occurred under the top roller. For the second sample, a fiberglass pad of $6.4 \mathrm{~mm} \times 19 \mathrm{~mm} \times 2.5 \mathrm{~mm}(0.25$ " 0.75 "x 0.097 ") was inserted between the 
roller and the sample to reduce the contact stress. However, failure again occurred under the roller. For the final sample, a rubber pad of $9.5 \mathrm{~mm} \times 25 \mathrm{~mm} \times 4.6 \mathrm{~mm}(0.375$ "x 1.0 "x 0.18 ") was used, but once again the sample failed under the roller. These configurations are shown in figure 5, with figure 5a showing sample 1 in failure.

The piezoelectric-embedded samples did not require pads below the rollers. Figure 6 shows a piezoelectric-embedded sample in the four-point loading fixture. The failure can be clearly seen at the top, compression surface of the sample. Figure 7 is a close-up of a failure, showing the delamination that occurred in the compression side of the beam. All the piezoelectric-embedded samples failed on the compression side, at the interface of the piezoelectric patch with the composite material. The maximum bending stress (outer surface, mid-span) at failure for baseline and embedded samples are shown in Figure 8. The error bars indicate the range of results, and $\mathrm{n}$ is the number of samples for each configuration.

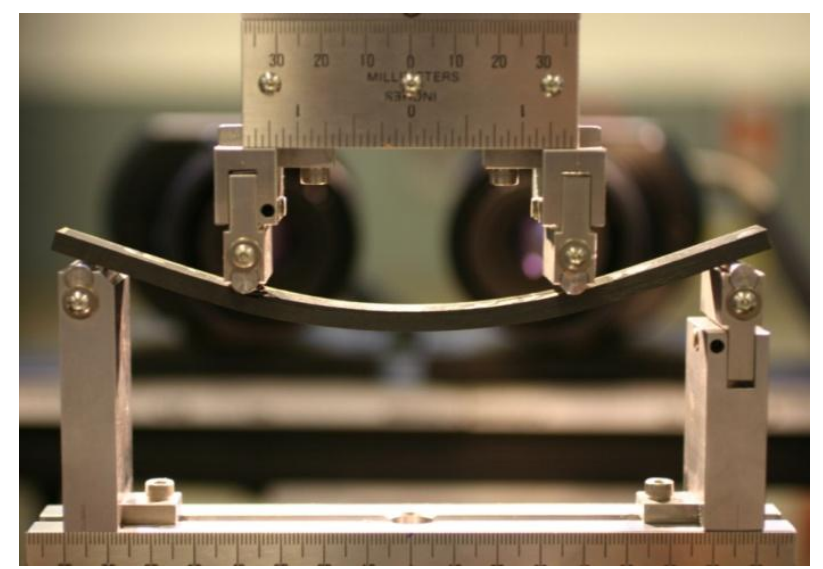

Figure 4. Four-point bending test configuration.

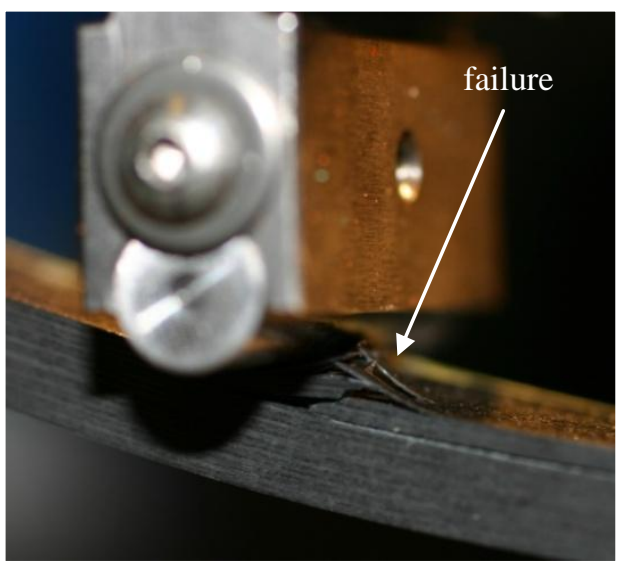

(a) Baseline sample 1 No pad

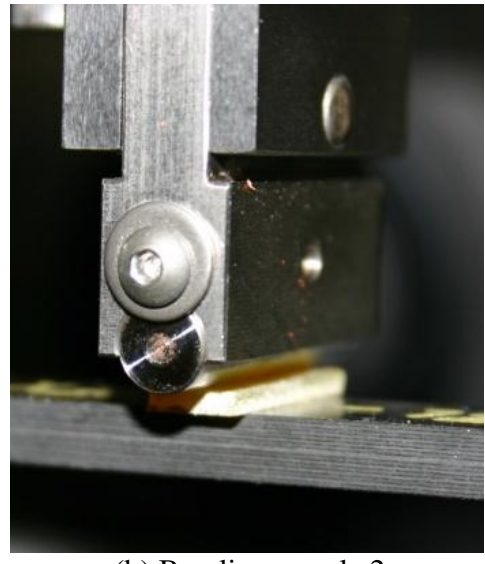

(b) Baseline sample 2 Fiberglass pad

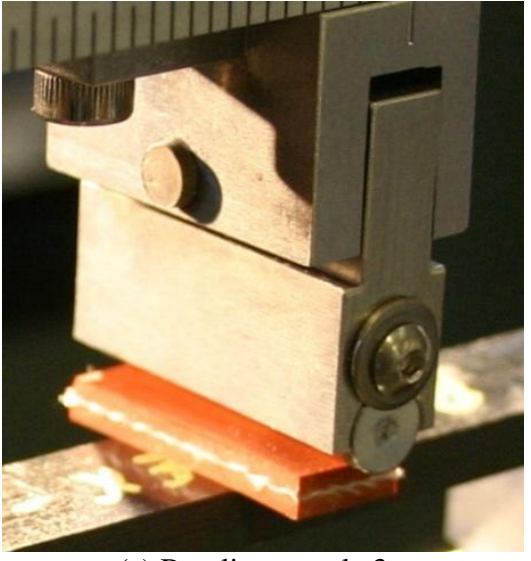

(c) Baseline sample 3 Rubber pad

Figure 5. Loading configurations for the baseline samples. 


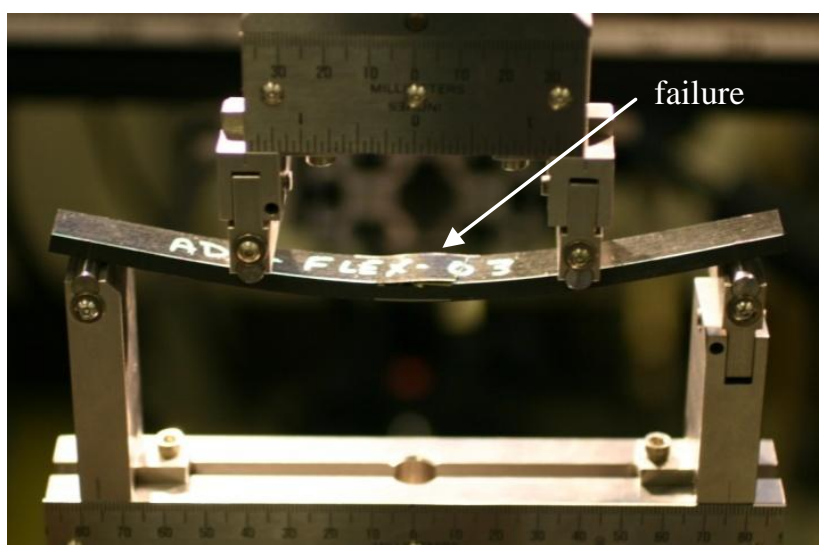

Figure 6. Piezoelectric-embedded sample failure in four-point bending fixture.

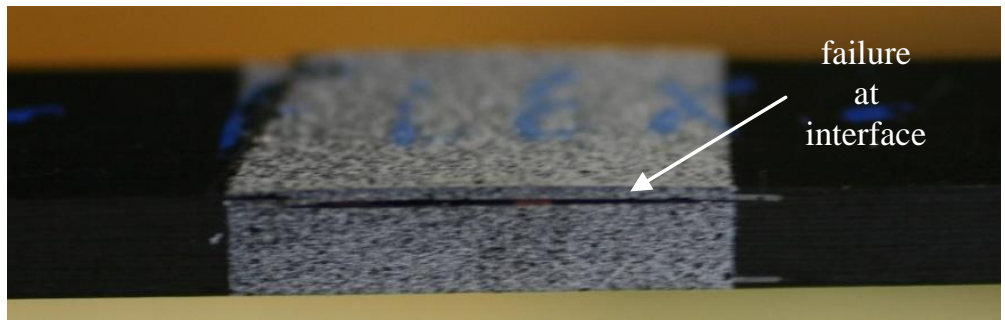

Figure 7. Piezoelectric-embedded sample four-point bending failure.

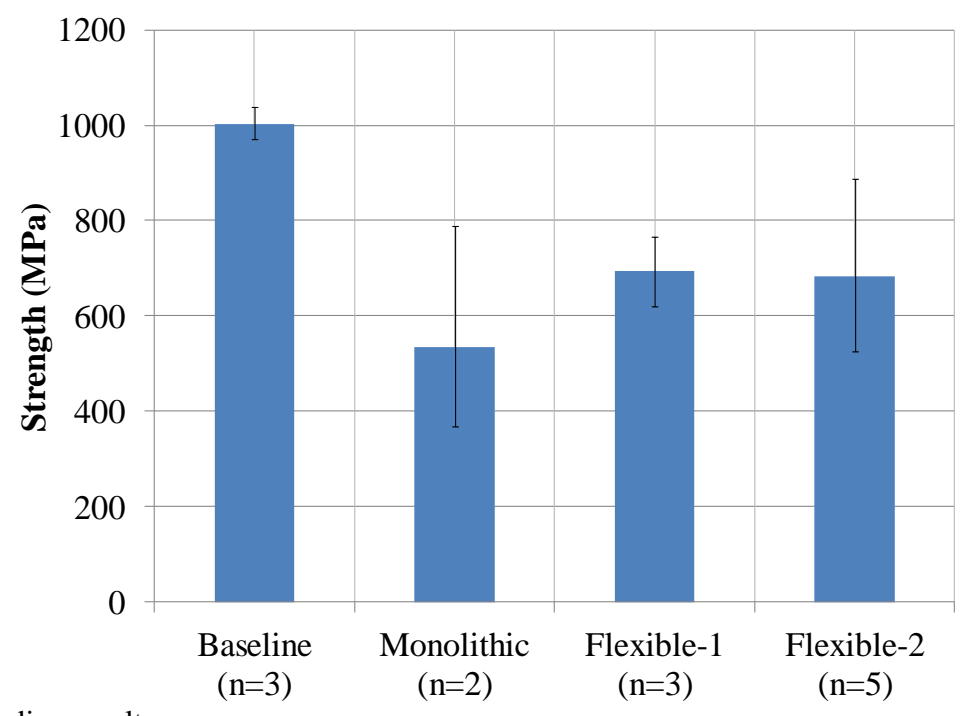

Figure 8. Four-point bending results.

The flexible piezoelectric-embedded samples showed an average strength reduction of 31-32\% compared to the baseline. The monolithic piezoelectric sample had an average strength reduction of 47\%. It was expected that the flexible patches would be more favorable in bending because their elastic modulus along the fiber direction is less than half that of the monolithic material. It is important to note that the baseline results do not reflect the actual bending strength of the composite material, since the failure mechanism was different. The typical failure mode for the composite material in 
four-point bending is fiber buckling on the compression side between the two load pins. This usually occurs at around 1200-1400 MPa.

Figure 9 shows the photogrammetry results for shear strain in typical baseline and piezoelectric-embedded specimens, immediately prior to failure. In the piezoelectric-embedded samples, there was significantly higher shear strain in the composite layer near the surface, adjacent to the piezoelectric patch, indicating the cause of failure.
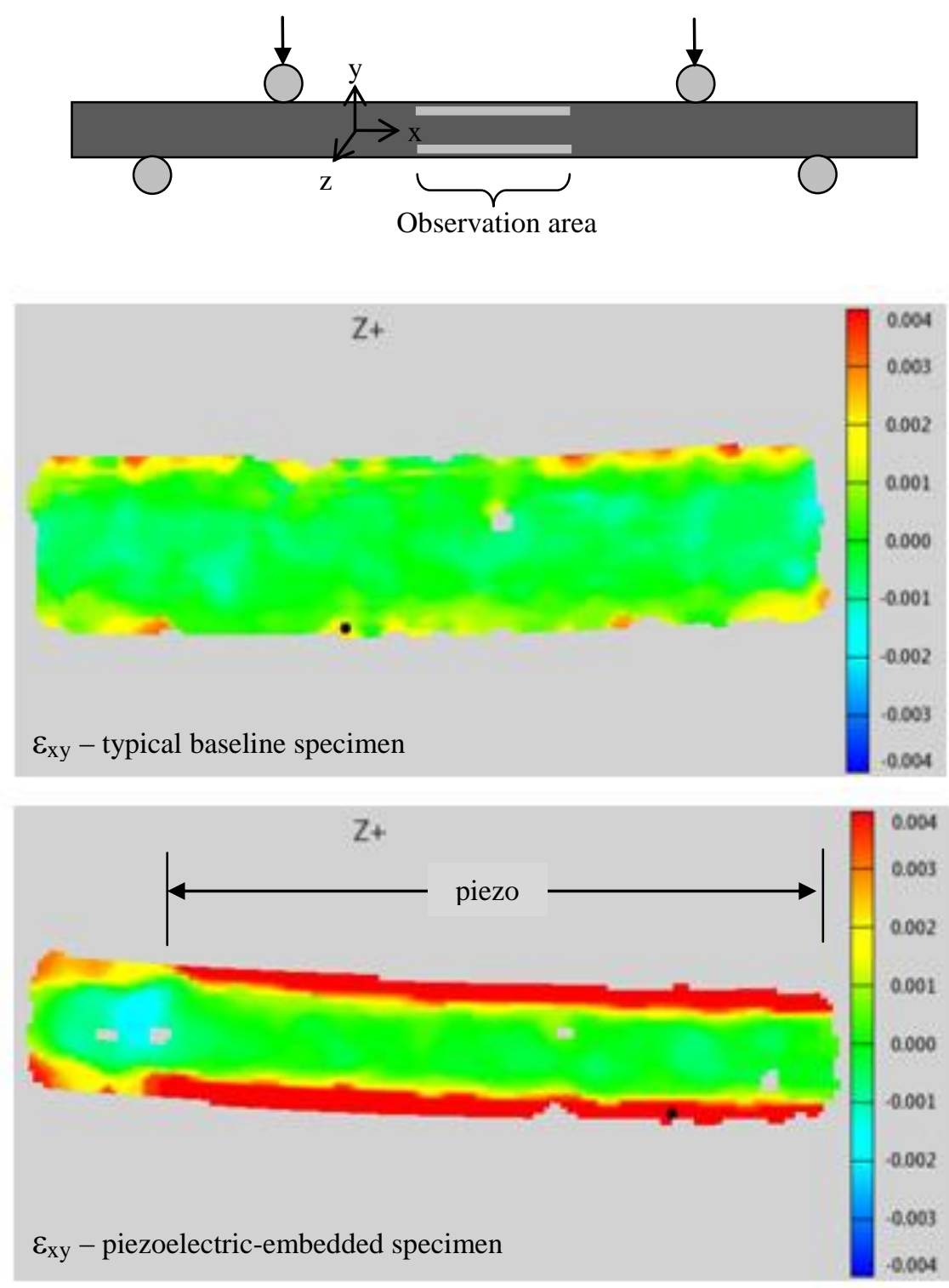

Figure 9. Four-point bending shear strain fields prior to failure. 


\subsection{Short beam shear test results}

The short beam shear test configuration is shown in figure 10. The failure mechanism for all the samples was interlaminar shear. The baseline samples experienced interlaminar shear with inelastic deformation, and the piezoelectric-embedded samples had interlaminar shear at the interface plane between the piezoelectric element and the composite material. Figure 11 shows the reduction in shear strength at the midplane due to the inclusion of the piezoelectric elements. The error bars indicate the range of results. The monolithic piezoelectric-embedded samples had an average shear strength reduction of 19\%, and the flexible piezoelectric-embedded samples had a reduction of 27-29\%.

Figure 12 shows the short beam shear test normal strains in typical specimens, immediately prior to failure. The interlaminar tensile strains throughout the piezoelectric layer plane can be seen, indicating a tendency to separate. In fact, this was observed in the sample failure shown in Figure $10 \mathrm{~b}$.

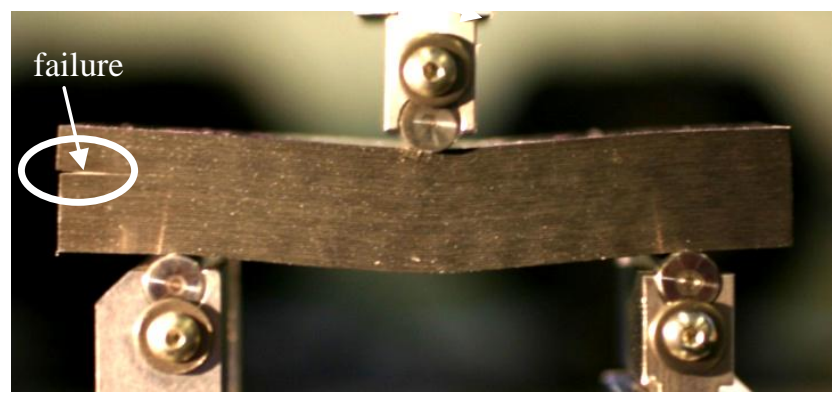

(a) Baseline

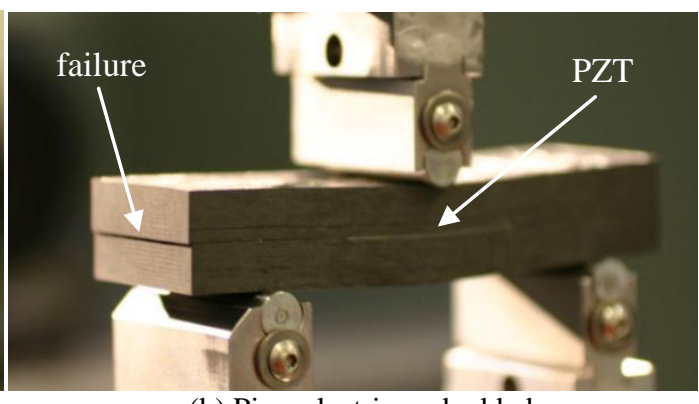

(b) Piezoelectric-embedded

Figure 10. Short beam shear test configurations with failed samples.

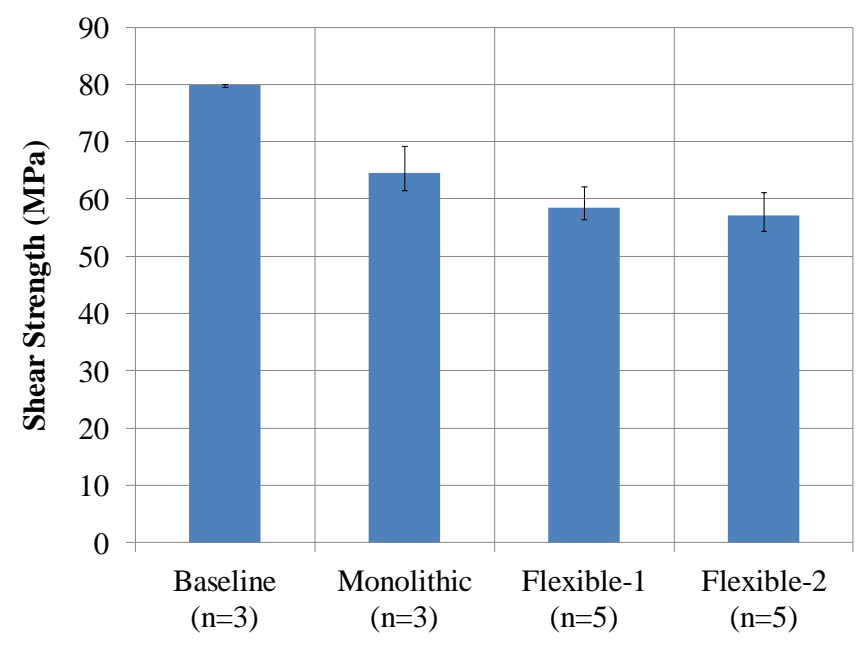

Figure 11. Short beam shear test results.

\subsection{Flatwise tensile test results}

The flatwise tensile test showed the greatest difference between the baseline and the piezoelectric-embedded specimens. The failure mechanism for the baseline samples was primarily due to debonding of the sample from the test fixture. One baseline sample showed delamination in the PMFC. The piezoelectric-embedded specimens all failed at the piezoelectric element, either at an epoxy layer or within the piezoelectric material itself.

Some of the embedded samples did not have a full layer of piezoelectric material within the specimen, indicating that the samples were sectioned off-center of the piezoelectric element. This yielded a void at the edge of the sample. Figure 13a shows one of these specimens. The void at the edge initiated an early failure within these samples. Other samples 
show failure within the piezoelectric patch itself (figure 13b). This is substantiated by photogrammetry results showing high normal strains in the piezoelectric location. However, regardless of failure mechanism, all the piezoelectricembedded samples failed at similar stress levels, in a fairly narrow range (figure 14). Moreover, all piezoelectricembedded composite samples failed at a much lower level than the baseline samples (83-85\% lower), even though the baseline samples failed in the epoxy attachment rather than in the material itself.
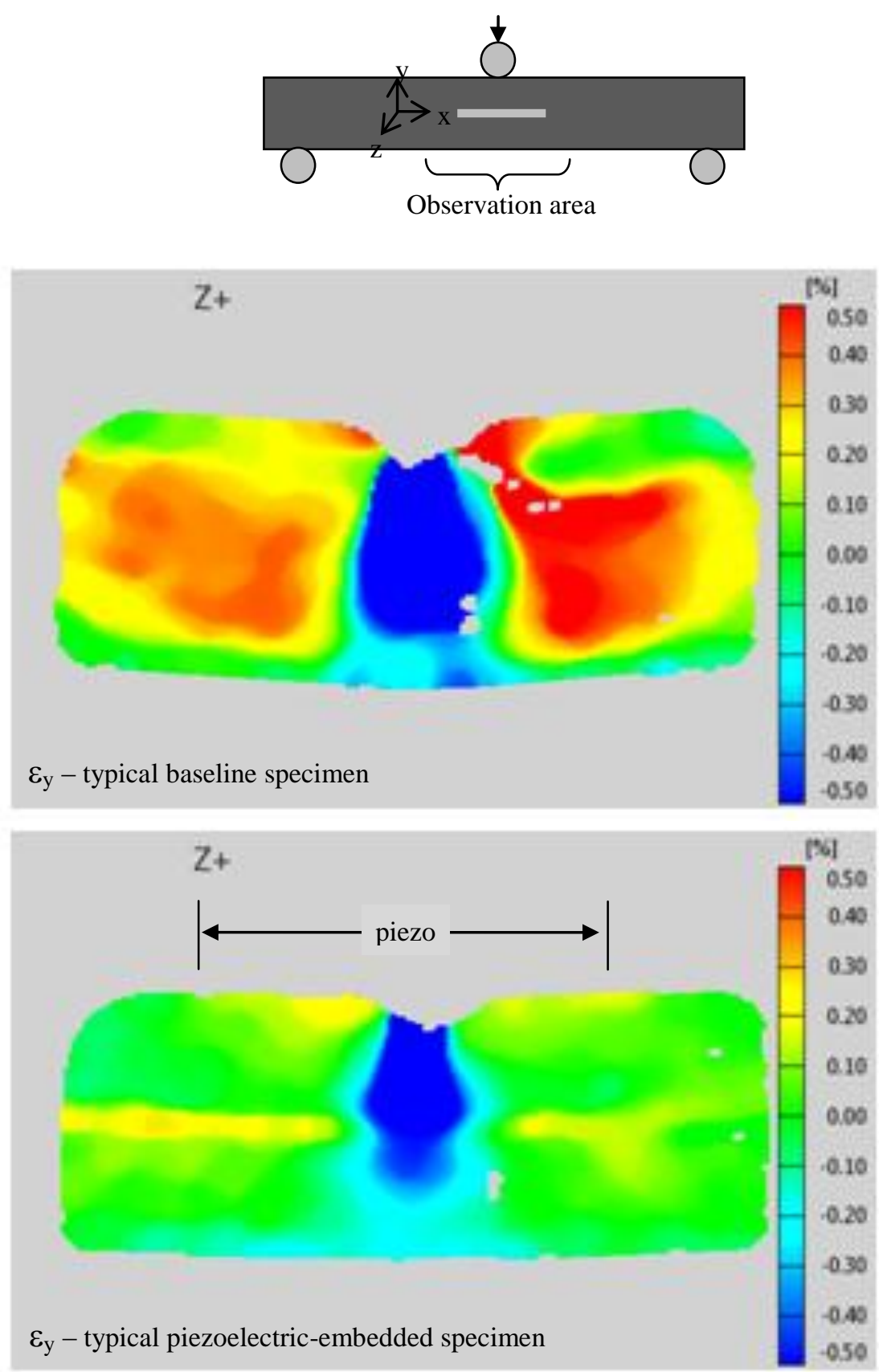

Figure 12. Short beam shear strain fields prior to failure. 


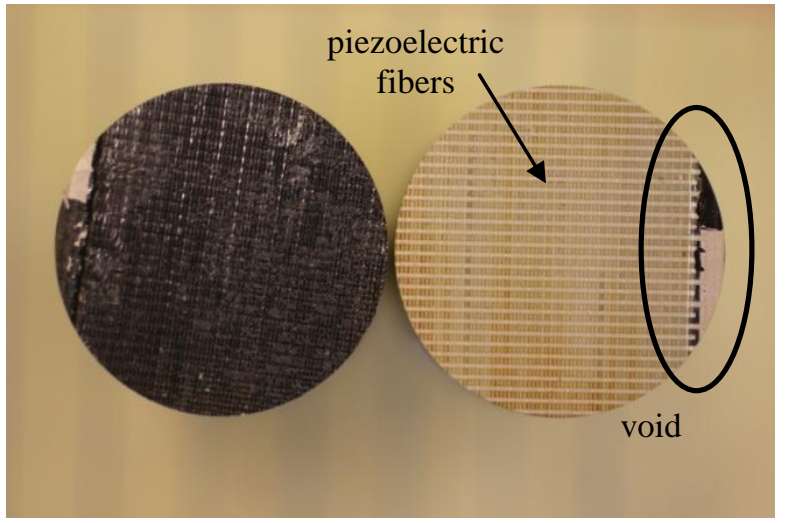

(a) Failure within patch at interface Flexible-2

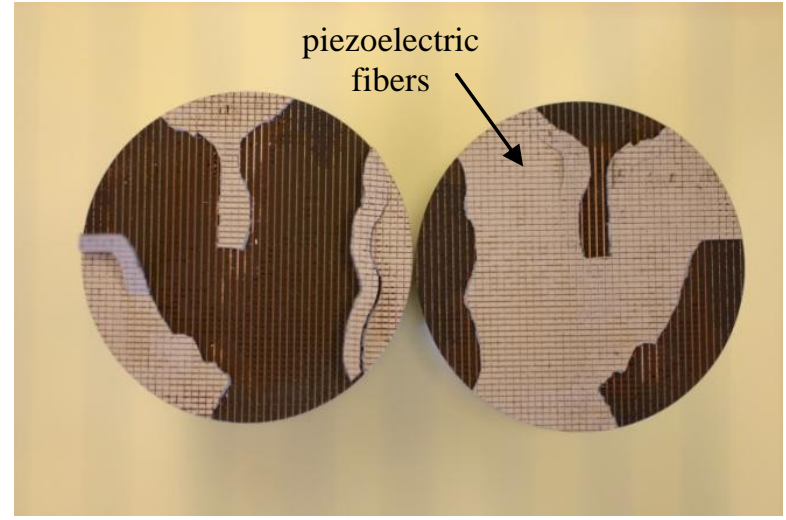

(b) Failure within patch at piezoelectric Flexible-1

Figure 13. Flatwise tension test failure examples.

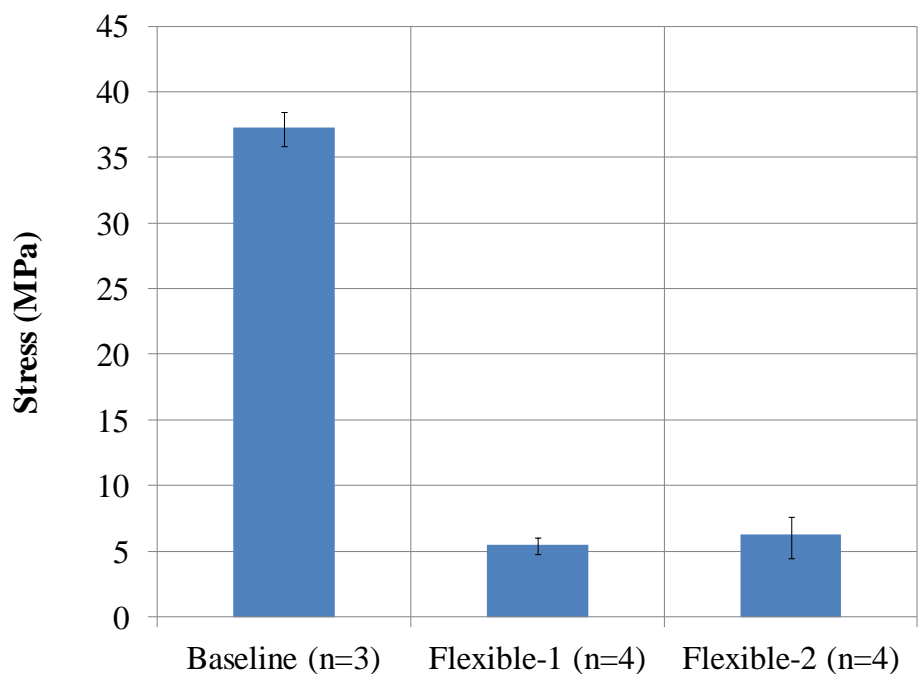

Figure 14. Flatwise tension test results.

\section{VIBRATION TESTING}

Vibration testing was performed to verify the performance of the piezoelectric sensors after embedding and curing. The Flexible-1 piezoelectric patch type was embedded into composite cantilever beams, and vibration tested in the first bending mode. The sensor voltage output was correlated to the calculated patch strain based on the beam tip deflection.

\subsection{Vibration testing setup}

Beam samples were tested in vibration to determine the sensing, actuation, and vibration damping abilities of the Flexible-1 type of piezoelectric patch. Table 3 shows the configurations tested. There were two beams tested for each configuration, for a total of four beams. Each beam was $5.66 \mathrm{~mm}(0.223$ inches) thick and held at one end with a clamp, the beam cantilevered so that $191 \mathrm{~mm}$ (7.5 inches) extended from the clamp. The beam width was chosen to be at least twice as wide as the PZT patch. Two piezoelectric patches were placed on either side of the beam, embedded either 0.30 $\mathrm{mm}(0.012$ inches) or $1.52 \mathrm{~mm}$ (0.060 inches) under the beam surface. Each patch will produce a voltage that depends on the strain induced within it. This sensitivity is based on the material properties, and is calculated from $S=$ $C /\left(E d_{31} L w\right)$, where $S$ is the sensitivity, $C$ is the embedded patch capacitance, $E$ is the patch elastic modulus along the 
piezoelectric fiber length direction, and $L$ and $w$ are the patch length and width. The capacitance used to determine the sensitivity was directly measured from the embedded patches.

Figure 15 shows the dimensions and arrangement of the vibration beam with the embedded Flexible- 1 patch. The piezoelectric patch was centered within the beam width, and placed so that one end of the piezoelectric active area lined up with the end of the clamp area. This location was chosen to coincide with the highest modal strain area in the beam for the first bending mode, which had a frequency of approximately $170 \mathrm{~Hz}$.

Table 3. Vibration test configurations.

\begin{tabular}{|c|c|c|c|c|c|}
\hline $\begin{array}{c}\text { Beam Dimensions } \\
\text { (Beyond Clamp) }\end{array}$ & $\begin{array}{c}\text { Patch } \\
\text { Dimensions }\end{array}$ & $\begin{array}{c}\text { Patch } \\
\text { Properties }\end{array}$ & $\begin{array}{c}\text { Patch } \\
\text { Sensitivity }\end{array}$ & $\begin{array}{c}\text { Configuration } \\
\text { ID }\end{array}$ & $\begin{array}{c}\text { Embedding } \\
\text { Depth }\end{array}$ \\
\hline \multirow{2}{*}{$\begin{array}{c}191 \mathrm{~mm}(7.5 ") \text { long } \\
33.0 \mathrm{~mm}(1.3 ") \text { wide } \\
5.66 \mathrm{~mm}(0.223 ”) \text { thick }\end{array}$} & \multirow{2}{*}{$\begin{array}{c}28.0 \mathrm{~mm} \times 14.0 \mathrm{~mm} \\
(1.10 " \mathrm{x} 0.55 ")\end{array}$} & \multirow{2}{*}{$\begin{array}{c}\mathrm{C}=25 \mathrm{nF} \\
\mathrm{E}=30.3 \mathrm{GPa} \\
\mathrm{d}_{31}=-210 \mathrm{pC} / \mathrm{N}\end{array}$} & \multirow{2}{*}{$\begin{array}{l}10 \times 10^{-6} \\
\mathrm{~m} / \mathrm{m} / \mathrm{V}\end{array}$} & Flexible-1-1 & $\begin{array}{c}0.3 \mathrm{~mm} \\
(0.012 ") \text { deep }\end{array}$ \\
\hline & & & & Flexible-1-2 & $\begin{array}{c}1.5 \mathrm{~mm} \\
(0.060 ") \text { deep }\end{array}$ \\
\hline
\end{tabular}

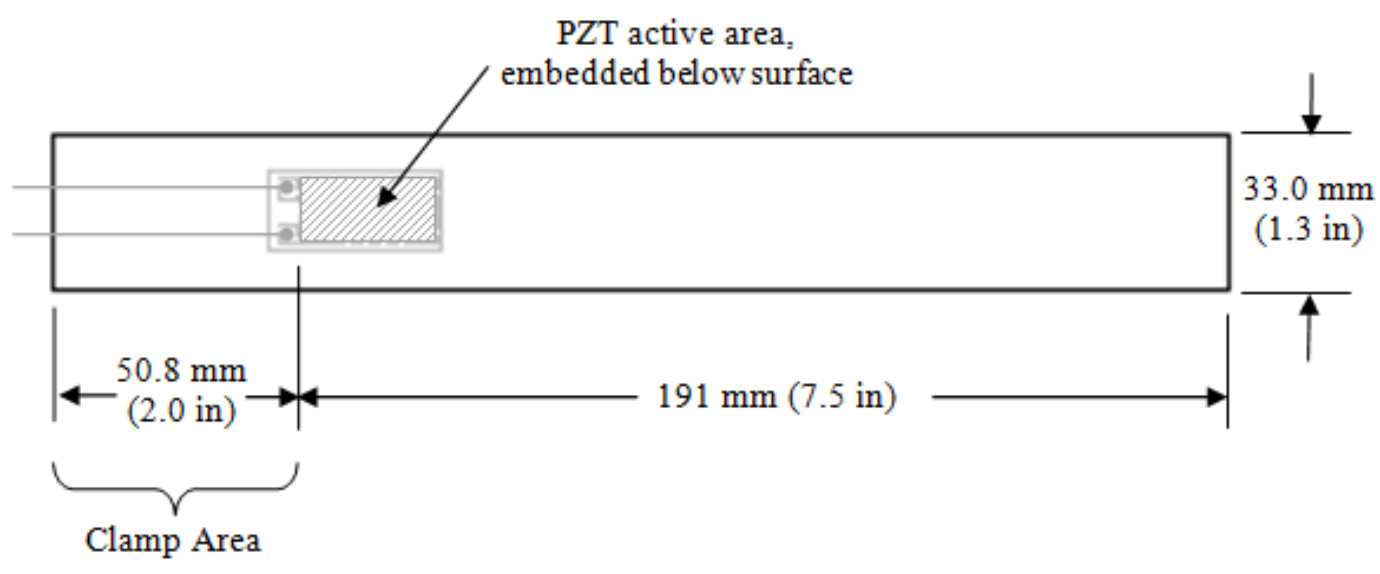

Figure 15. Dimensions and layout of the beam with Flexible-1 piezoelectric patches embedded within.

The vibration testing was conducted according to ASTM standard E756-05, "Standard test method for measuring vibration-damping properties of materials." 16 The beams were mounted on a MB Dynamics 100-lbf shaker. A Columbia 6062-HT charge accelerometer was placed on the clamp to measure the base acceleration. The beam tip response was measured by either an identical charge accelerometer measuring acceleration, or a laser Doppler vibrometer measuring velocity. The vibrometer consists of a Polytec OFV-505-LR sensor head and a OFV-5000 controller with VD-01 velocity decoder.

To determine the sensing capabilities of the piezoelectric patches, a frequency sweep was performed across the first bending mode frequency using the shaker as excitation. The output of the base accelerometer was used to determine the excitation level. The output of the tip sensor (accelerometer or laser) was used to determine the beam response. The beam tip displacement amplitude was calculated from the velocity or acceleration amplitude, assuming harmonic motion. The output of each piezoelectric patch was used to directly calculate the average strain level in the patch.

\subsection{Vibration testing results}

The bending strain in each embedded patch should be proportional to the distance of the patch from the neutral axis. The Flexible-1-1 patch has a neutral axis distance of $2.39 \mathrm{~mm}$, and the Flexible-1-2 patch has a neutral axis distance of 1.24 
mm. Therefore, the expected voltage output of Flexible-1-2 should be about 48\% lower than that of Flexible-1-1. The output of each piezoelectric sensor versus tip displacement is given in Figure 16a, which shows the reduced sensor output of the more deeply-embedded sensor.

The piezoelectric sensor strain was determined based on the sensor voltage output and a sensitivity of $10 \times 10^{-6} \mathrm{~m} / \mathrm{m} / \mathrm{V}$, and is shown in Figure 16b. The "calculated strain" is the average strain in the piezoelectric sensor for a given beam tip deflection, as determined using Ansys Workbench with a harmonic acceleration at the beam base. The piezoelectric sensor strain correlates well with the calculated strain, indicating that the sensors are functioning as expected.

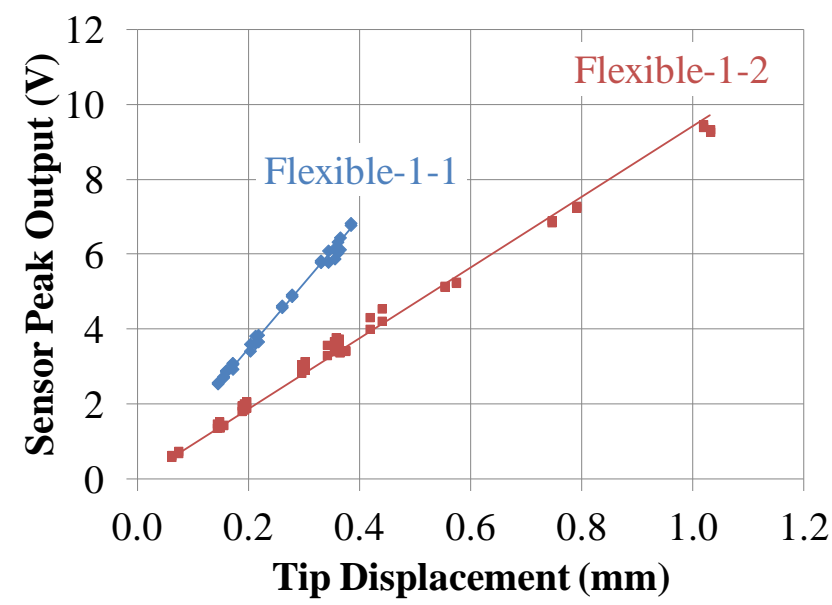

(a) Sensor voltage output

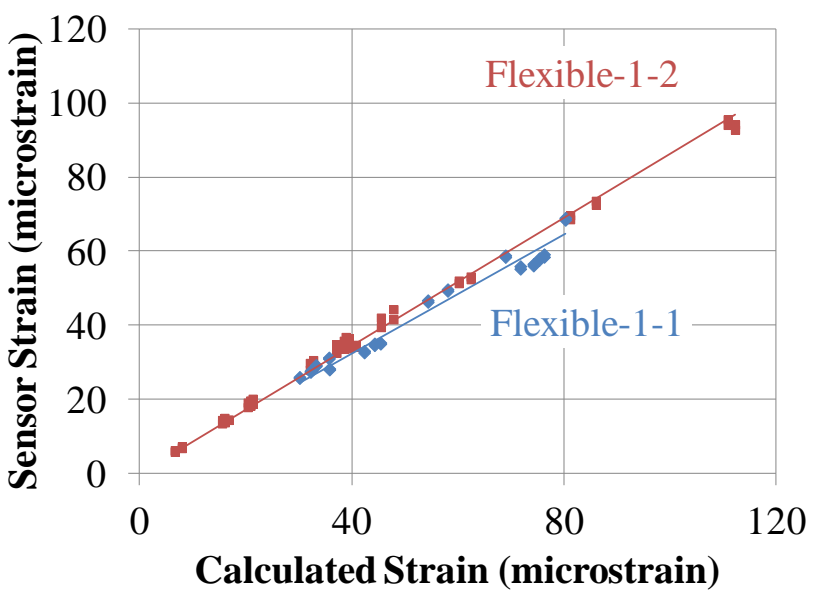

(b) Sensor strain

Figure 16. Piezoelectric sensor results.

\section{CONCLUSIONS}

In order to determine the viability of using piezoelectric sensors and actuators within polymer matrix fiber composite fan blades, mechanical and vibration testing was carried out to determine any detrimental effects caused by embedding. Four-point bending, short beam shear, and flatwise tension tests were performed on specimens with and without piezoelectric patches. The piezoelectric material was Navy Type-II PZT (PZT-5A). The piezoelectric elements included a non-flexible patch incorporating a solid piece of PZT, and two different flexible patches incorporating PZT fibers. Unlike past testing, these specimens were fabricated with the piezoelectric element occupying a full layer within the test specimen, in the direction or plane transverse to the induced stress. The piezoelectric-embedded samples showed reduced strength compared to the baseline samples in four-point bending (31-47\% reduction, depending on patch type), short beam shear (19-29\% reduction, depending on patch type), and, most significantly, flatwise tension (83-85\% reduction). These strengths are lower than those in prior testing published in the literature. However, prior testing was done on specimens where the piezoelectric element was fully surrounded by composite material in the plane of the piezoelectric element. Therefore those strengths did not reflect the local strength at the piezoelectric location; rather they reflected more of a global strength of the composite with an embedded inclusion.

Vibration testing showed that the embedded piezoelectric sensors that experienced curing temperature of $175^{\circ} \mathrm{C}\left(350^{\circ} \mathrm{F}\right)$ and $690 \mathrm{kPa}(100 \mathrm{psi})$ pressure functioned as expected, indicating little or no degradation of piezoelectric properties during specimen fabrication.

Depending on the application, a composite material with embedded piezoelectric elements may have adequate strength for implementation. However, in cases where the strength needs to be higher, methods for reducing interlaminar stresses between the composite and piezoelectric element should be investigated. For example, interlacing the composite plies with the piezoelectric elements could decrease stresses. ${ }^{17}$ However, this is unlikely to increase the flatwise tensile strength in cases where the failure occurred within the piezoelectric element itself. Each patch is comprised of the piezoelectric element, electrodes, kapton cover sheets, and epoxy. Developing techniques to increase the strength of this piezoelectric composite itself is essential prior to implementation within PMFC fan blades. 


\section{REFERENCES}

[1] Y. El-Aini, R. deLaneuville, A. Stoner, and V. Capece, "High cycle fatigue of turbomachinery components industry perspective," AIAA-1997-3365 (1997).

[2] I. Chopra, "Review of state of art of smart structures and integrated systems," AIAA Journal 40(11), 2145-2187 (2002).

[3] N. W. Hagood and A. von Flotow, "Damping of structural vibrations with piezoelectric materials and passive electrical networks," Journal of Sound and Vibration 146(2), 243-268 (1991).

[4] G. A. Lesieutre, "Vibration damping and control using shunted piezoelectric materials," The Shock and Vibration Digest 30(3), 187-195 (1998).

[5] D. J. Warkentin and E. F. Crawley, "Embedded electronics for intelligent structures," AIAA-91-2064-CP (1991).

[6] A. J. Bronowicki, L. J. McIntyre, R. S. Betros, and G. R. Dvorsky, "Mechanical validation of smart structures," Smart Materials and Structures 5, 129-139 (1996).

[7] S. Mall and J. M. Coleman, "Monotonic and fatigue loading behavior of quasi-isotropic graphite/epoxy laminate embedded with piezoelectric sensor," Smart Materials and Structures 7, 822-832 (1998).

[8] S. Mall and T. L Hsu, "Electromechanical fatigue behavior of graphite/epoxy laminate embedded with piezoelectric actuator," Smart Materials and Structures 9, pp. 78-84 (2000).

[9] C. A. Paget and K. Levin, "Structural integrity of composites with embedded piezoelectric ceramic transducer," Proceedings of SPIE Conference on Smart Structures and Integrated Systems, 3688 (1999).

[10] M. Lin and F.-K. Chang, "The manufacture of composite structures with a built-in network of piezoceramics," Composite Science and Technology 62, pp. 919-939 (2002).

[11] H. P. Konka, M. A. Wahab, and K. Lian, "On mechanical properties of composite sandwich structures with embedded piezoelectric fiber composite sensors," Journal of Engineering Materials and Technology, 134 (2012).

[12] R. G. Bryant, "Overview of NASA Langley's piezoelectric ceramic packaging technology and applications," NASA Technical Report, Document ID: 20080000875 (2007).

[13] "Standard test method for flexural properties of polymer matrix composite materials," ASTM standard D7264 (2007).

[14] "Standard test method for short beam strength of polymer matrix composite materials and their laminates," ASTM D2344 (2006).

[15] "Standard test method for through thickness flatwise tensile strength and elastic modulus of a fiber reinforced polymer matrix composite material," ASTM D7291 (2007).

[16] "Standard test method for measuring vibration-damping properties of materials," ASTM standard E756-05 (2008).

[17] David A. Singh and Anthony J. Vizzini, "Structural integrity of composite laminates with interlaced actuators," Smart Materials and Structures 3, pp. $71-79$ (1994). 